\title{
Conservação de filés de tilápia-do-nilo (Oreochromis niloticus) em salga seca e salga úmida
}

[Nile tilapia (Oreochromis niloticus) preservation by means of dry salting and saturated brine]

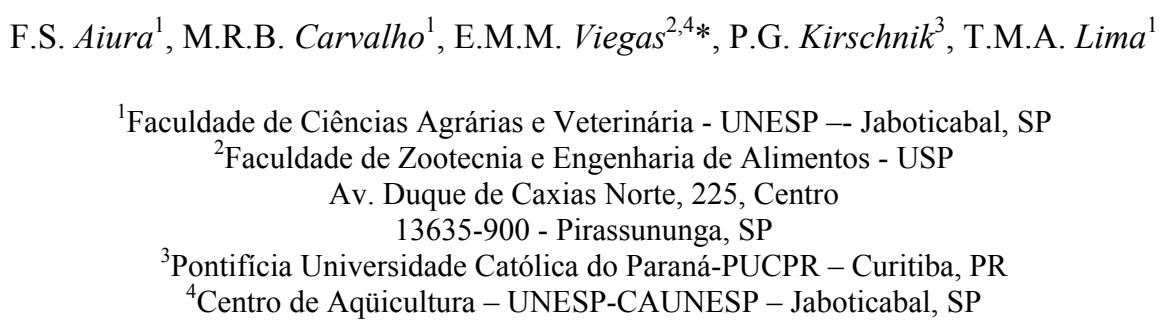

\section{RESUMO}

Acompanhou-se o desenvolvimento dos processos da salga em salmoura saturada (salga úmida) e salga seca de filés de tilápia-do-nilo (Oreochromis niloticus) e avaliaram-se algumas características indicativas de qualidade do produto durante a estocagem. Os processos foram acompanhados por 156 horas na salga úmida e por 96 horas na salga seca, e os filés salgados foram estocados, respectivamente, por 60 e 45 dias à temperatura ambiente. Os teores máximos de cloreto nos filés (14\%) foram atingidos com 72 horas na salga úmida e com 36 horas na salga seca. Os filés de tilápia salgados em salmoura mantiveram as características próprias do produto por um período de 45 dias, e os submetidos à salga seca apresentaram baixo teor de umidade $(6 \%)$ e alta concentração de extrato etéreo (4,6\%). Recomenda-se somente o processo de salga em salmoura saturada como forma de conservação dos filés de tilápia-do-nilo.

Palavras-chave: peixe, métodos de salga, rancificação, tilápia-do-nilo, estocagem

\section{ABSTRACT}

The processes of salting of Nile tilapia fillets (Oreochromis niloticus) submitted to saturated brine and dry salting were observed, and some characteristics that indicate the quality of the product during the storage were evaluated. The brine saturated process was followed up to 156 hours and the dry salting was followed up to 96 hours. When the salting finished, fillets were stored for 45 (dry salting) and 60 days (saturated brine), respectively. The highest values for chloride in fillets (14\%) were reached within 72 hours in brine salting and 36 hours in dry salting. The tilapia fillets salted in brine kept the proper characteristics of the product for a period of 45 days and the fillets submitted to dry salting showed low moisture ratios (6\%) and a high concentration of lipids (4.6\%). Thereby, it is only recommended the salting process in saturated brine to be used as a mean of conservation for Nile tilapia fillets.

Keywords: fish, salting methods, rancidity, Nile tilapia, storage

\section{INTRODUÇÃO}

O princípio básico da salga consiste na remoção de certa quantidade de água do músculo do peixe e sua parcial substituição por sal. O objetivo dessa operação é diminuir a atividade de água
(Aa) do produto para aumentar sua estabilidade microbiana, química e bioquímica e também contribuir para o desenvolvimento de características desejáveis de aroma e sabor nos produtos (Chiralt et al., 2001).

Recebido em 2 de janeiro de 2007

Aceito em 10 de outubro de 2008

*Autor para correspondência (corresponding author)

E-mail: emviegas@usp.br 
Durante o processo de salga, os íons de sódio e cloro são transportados da salmoura para o interior do pescado, e a água deste, para a salmoura. O transporte ocorre em intensidades diferentes durante a salga, sendo a concentração de cloreto de sódio, existente no tecido muscular do pescado e na salmoura, o fator mais importante, como determinante da intensidade do transporte das substâncias participantes no processo (Shenderyuk e Bylowski, 1990).

Produtos com altos teores de sal, como o pescado salgado e seco, são considerados de fácil conservação, apesar de não estarem livres de sofrer deterioração, química ou microbiológica, circunstâncias que desfavorecem o maior consumo dos produtos da pesca. A penetração de cloreto de sódio nos tecidos é acompanhada por intensa desidratação e precipitação de proteínas musculares, quando em concentrações acima de 8\% (Ogawa, 1999).

Métodos mais recentes de salga, como, por exemplo, injeção de salmoura têm sido usados para produtos de peixe levemente salgados. O conteúdo de sal no produto final é bem menor $( \pm 2 \%)$, e os produtos não precisam ser reidratados antes do consumo como o bacalhau fortemente salgado (Thorarinsdottir et al., 2002). Chiralt et al. (2001) discutem a utilização de um processo recente com aplicação de vácuo da salga, o qual reduz o tempo de salga e aumenta o rendimento do processo.

Devido ao aumento significativo na produção de tilápias em cativeiro no Brasil, o desenvolvimento de métodos de salga que proporcionem a elaboração de pescados salgados de qualidade pode ser uma forma de fornecer subsídios aos produtores rurais de como preservar o produto, possibilitando, assim, agregar valor a sua produção, de uma forma simples e pouco dispendiosa, uma vez que não requer equipamentos sofisticados para o processamento do produto. A conservação de tais produtos, à temperatura ambiente, constitui um ponto de máxima importância nos países em desenvolvimento, que apresentam deficiências referentes à instalação para armazenamento sob refrigeração (Shenderyuk e Bylowski, 1990).

Os objetivos deste trabalho foram acompanhar o desenvolvimento dos processos de salga seca e úmida de filés de tilápia-do-nilo e avaliar a qualidade dos filés salgados durante a estocagem, em termos de rancidez oxidativa, composição centesimal e rendimento.

\section{MATERIAL E MÉTODOS}

Para a salga em salmoura saturada (salga úmida), foram utilizadas 22 tilápias-do-nilo (Oreochromis niloticus), pesando em média $976,63 \mathrm{~g} \pm 372,68 \mathrm{~g}$, e, para a salga seca, 46 peixes, com média de peso de $482,64 \mathrm{~g} \pm 86,67 \mathrm{~g}$.

Os peixes foram insensibilizados por choque térmico e mortos pela destruição medular. Após o abate, foram pesados, descamados e deles obtidos os filés. A proporção salmoura:filé foi de $2: 1$, e a salga úmida foi realizada por aproximadamente seis dias (156 horas). No final do período, os filés foram pesados e prensados por 24 horas, sob pressão de aproximadamente cinco vezes o seu peso. A secagem foi realizada em estufa com circulação de ar à temperatura de $40^{\circ} \mathrm{C}$ durante três dias, e a estocagem dos filés salgados, por 60 dias, ocorreu à temperatura ambiente. Para a salga seca, os filés foram empilhados sobre uma madeira perfurada, sendo intercalados por camadas de sal grosso. O processo ocorreu por 96 horas. A secagem foi realizada durante 48 horas a $40^{\circ} \mathrm{C}$ e a estocagem por 45 dias.

O acompanhamento dos processos de salga foi realizado até que o conteúdo de sal no músculo atingisse aproximadamente 14\%. Nos filés (cinco amostras) foram determinados, em duplicata, os teores de umidade segundo a AOAC (Official..., 1990), de cloreto de sódio segundo o Lanara (Métodos..., 1993) e o de substâncias reativas ao ácido tiobarbitúrico (TBARS) (Vyncke, 1970). $\mathrm{Na}$ salmoura analisaram-se os teores de cloreto de sódio e de proteínas solúveis (Hartree, 1972).

A composição centesimal (Official...,1990) e o rendimento dos filés foram determinados, em duplicata, na matéria prima inicial, após prensagem e secagem e no final da estocagem.

A análise estatística dos resultados para composição centesimal e rendimento dos filés foi realizada utilizando o delineamento inteiramente ao acaso, com cinco repetições. As análises de variância e a de regressão foram realizadas utilizando-se o programa computacional SAS 
(User's..., 1989). As médias foram comparadas pelo teste Tukey a $5 \%$ de probabilidade.

\section{RESULTADOS E DISCUSSÃO}

A Fig. 1 (A e B) representa os valores médios para porcentagem de umidade no músculo dos peixes nos processos de salga em salmoura saturada e seca, respectivamente. $\mathrm{O}$ teor de umidade diminuiu em torno de $22 \%$, durante as

A

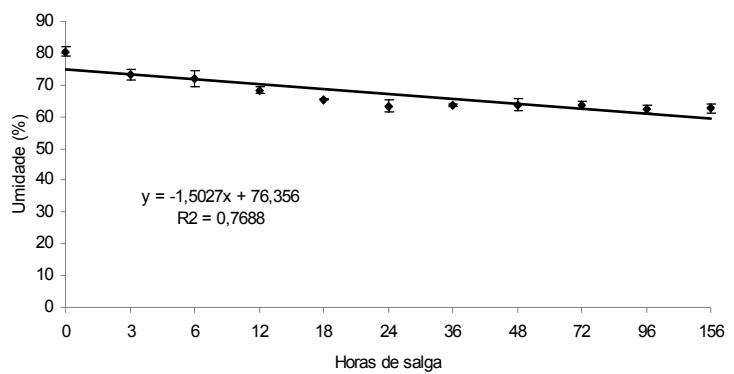

156 horas de salga no processo de salmoura saturada. O valor inicial de $80,4 \%$ reduziu-se para $73,2 \%$ nas primeiras três horas de salga. A diminuição do teor de água continuou a ocorrer, quase de maneira uniforme até 24 horas, estabilizando-se ao redor de $69 \%$. No processo da salga seca, a queda nos teores de umidade foi mais intensa e linear, atingindo aproximadamente $50 \%$ após 96 horas de salga.

B

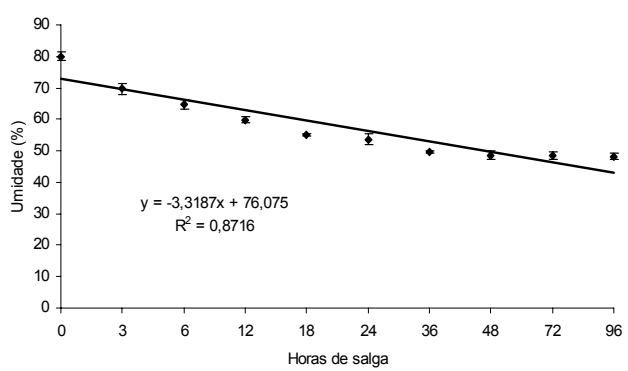

Figura 1. Valores médios para porcentagem de umidade no músculo de tilápia-do-nilo, durante a salga em salmoura saturada (A) e durante a salga seca (B) (cinco amostras).

O valor inicial do cloreto muscular (Fig. 2) aumentou com o desenvolvimento da salga, atingindo valor em torno de $14 \%$ com 72 horas na salga úmida e com 36 horas na salga seca, provavelmente alcançando o equilíbrio osmótico. Observou-se aumento linear, $\mathrm{R}^{2}=0,9705$ e $\mathrm{R}^{2}=$ 0,8508 , respectivamente, para incorporação de sal no músculo durante o período da salga úmida e seca.

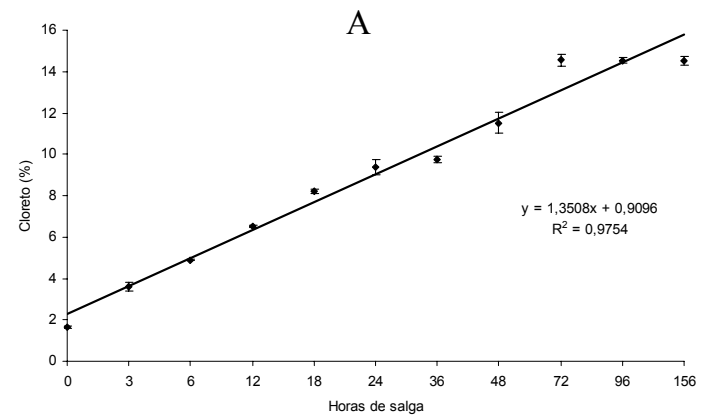

A concentração de sal no centro de um filé de $2,5 \mathrm{~cm}$ de espessura pode alcançar $10 \%$ após 24 horas na salmoura (Burgess et al., 1967). Essa situação também foi observada neste estudo, uma vez que os filés, com espessura em torno de $2 \mathrm{~cm}$, atingiram valor próximo a $10 \%$ após um dia na salga em salmoura saturada e ao redor de $8 \%$ na salga seca.

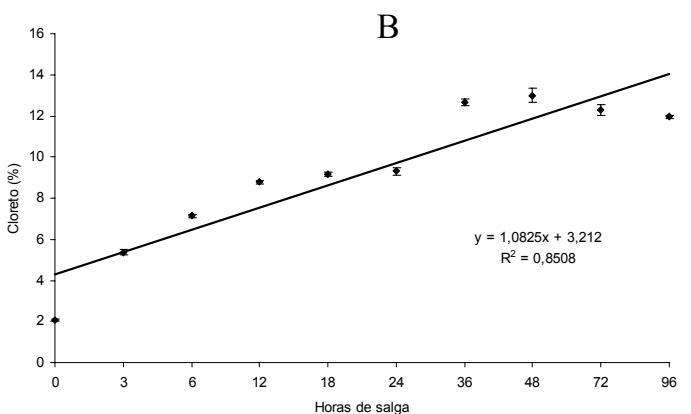

Figura 2. Valores médios para porcentagem de cloreto no músculo de tilápia-do-nilo, durante a salga em salmoura saturada (A) e durante a salga seca (B) (cinco amostras).

A diminuição no conteúdo inicial de cloreto na salmoura $(29,7 \%)$ foi mais bem acompanhada pela redução da umidade do filé $\left(\mathrm{r}=0,870^{* *}\right)$, do que com o incremento da concentração do cloreto no músculo $\left(r=-0,761^{* *}\right)$. No entanto, a mudança mais acentuada que ocorreu no músculo durante $\mathrm{o}$ processo de salga foi originada, principalmente, por quantidades crescentes de cloreto de sódio associada à redução do conteúdo de água $\left(\mathrm{r}=-0,893^{* *}\right)$. 
Assim, a diluição da salmoura foi provocada tanto pela penetração de sal no músculo, como pela liberação da água muscular para o sistema filé-salmoura.

Ogawa (1999) relatou que para a salga úmida com concentração acima de $15 \%$, ocorre redução da umidade do produto por desidratação, e um leve acréscimo pode ser observado, em conseqüência da mudança nas propriedades de absorção de água das proteínas musculares por ação do sal. Apesar de menos pronunciada, neste estudo observou-se ligeiro acréscimo do teor de umidade no período de 36 a 72 horas, nos dois tipos de salga.

A concentração de proteína solúvel na salmoura elevou-se com o desenvolvimento da salga e foi acompanhada pela perda de água nos filés $(\mathrm{r}=$ $0,9739)$. A presença de proteína na salmoura (lixiviada do músculo) pode ser devido ao fato de que, em elevadas concentrações salinas, as proteínas perdem a água de hidratação, possibilitando a formação de precipitado (Sgarbieri, 1996).

Os valores de TBARS dos filés, durante o processo da salga, são mostrados nas Tab. 1 e 2 . A rancidez apresentou-se baixa no início do processo da salga em salmoura com valores de TBARS de 0,50mg de malonaldeído $/ \mathrm{kg}$ de músculo, elevando-se com a prensagem $(1,80 \mathrm{mg} / \mathrm{kg}$ de músculo) e atingindo o máximo após a secagem $(2,25 \mathrm{mg} / \mathrm{kg})$. Para os filés submetidos à salga seca, o maior valor $(3,29 \mathrm{mg} / \mathrm{kg})$ também foi observado após a secagem. Estes foram mais altos que os obtidos por Boeri et al. (1982), para merluza salgada, e por Zapata et al. (1986), que obtiveram valores compreendidos entre 0,34 e 0,66 durante a salga de tilápia-do-nilo. No entanto, estão bem abaixo dos limites mínimos (4,0mg de malonaldeído/kg) registrados por Beraquet et al. (1983) durante a salga da cavalinha.
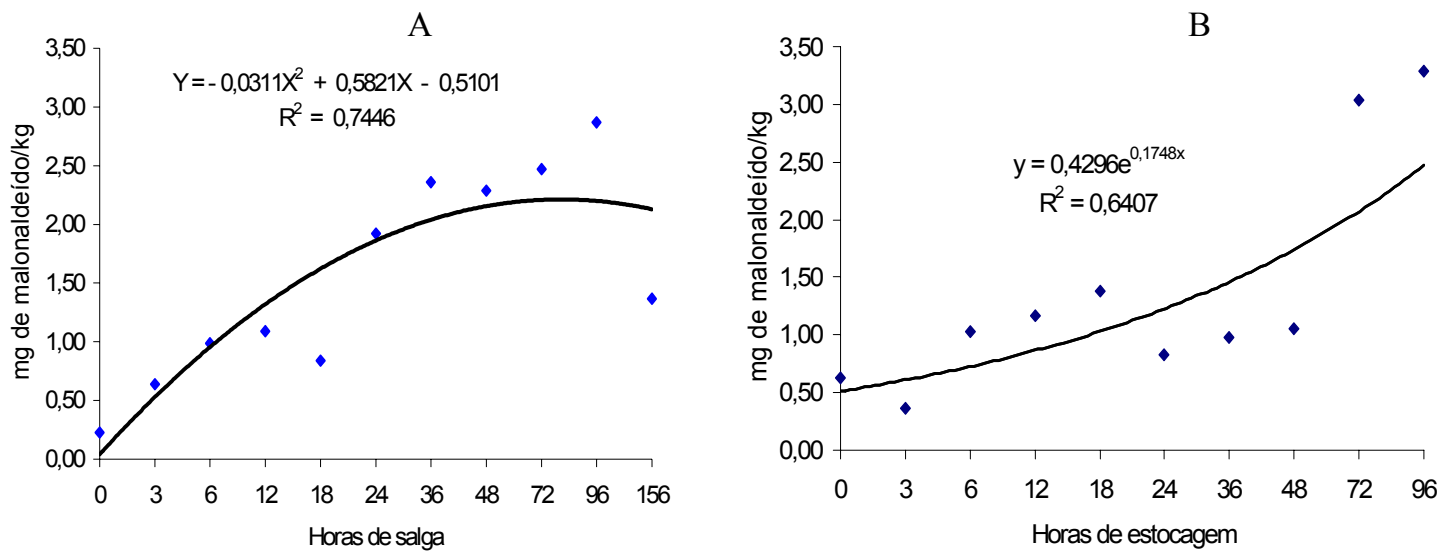

Figura 3. Valores médios de TBARS presentes no músculo de tilápia-do-nilo, durante a salga em salmoura saturada (A) e durante a salga seca (B) (cinco amostras).

Os valores de malonaldeído no músculo de tilápia-do-nilo para salga em salmoura saturada não aumentaram proporcionalmente com $\mathrm{o}$ tempo de salga, provavelmente devido aos baixos teores de lipídios nesses tecidos. A equação de regressão que melhor expressa essa situação é a quadrática, com coeficiente de determinação $\left(\mathrm{R}^{2}\right)$ de 0,7446 (Fig. 3A); para a salga seca (Fig. 3B), a equação é uma exponencial, embora com coeficiente de determinação relativamente baixo $\left(\mathrm{R}^{2}=0,6407\right)$.
No desenvolvimento da salga úmida, observouse às 18 horas e ao final do processo (156 horas), diminuição dos valores de TBARS. Essa situação também foi verificada por Beraquet et al. (1983) que atribuíram o decréscimo à lixiviação do malonaldeído para a salmoura. Isso não ocorreu na salga seca, observando-se valores crescentes de malonaldeído após 48 horas de salga.

Terminado o período de salga úmida (156 horas), os filés foram prensados e secos em estufa a $40^{\circ} \mathrm{C}$ durante três dias. Os filés de tilápia-do-nilo submetidos à salga em salmoura perderam cerca 
de $5 \%$ de água durante a prensagem, com aumento em torno de $3 \%$ na quantidade de sal nos filés (Tab. 1). Valores semelhantes para cloreto em produtos salgado $(14,7 \%)$ e prensado $(18,6 \%)$ foram obtidos em filé de bonito (Machado, 1984).
A porcentagem de umidade dos filés após a secagem foi reduzida para $33,9 \%$, e o conteúdo de sal elevou-se para 19,3\% (Tab. 2). Estes valores foram próximos aos obtidos por Machado (1984), ao analisar filés de pargo salgados e secos, em que o valor para umidade foi $39 \%$ e para cloreto, $19,5 \%$.

Tabela 1. Valores médios para composição centesimal e rendimento de filés de tilápia- do-nilo no início do processo de salga em salmoura saturada, após prensagem e após secagem

\begin{tabular}{lcccc}
\hline Componente (\%) & Início & Após prensagem & Após secagem & Produto final \\
\hline Umidade & $80,4 \mathrm{a}$ & $59,0 \mathrm{~b}$ & $29,2 \mathrm{c}$ & $16,5 \mathrm{~d}$ \\
Proteína & $14,8 \mathrm{a}$ & $20,1 \mathrm{~b}$ & $29,4 \mathrm{c}$ & $31,7 \mathrm{~d}$ \\
Extrato etéreo & $1,0 \mathrm{a}$ & $3,5 \mathrm{a}$ & $3,8 \mathrm{a}$ & $2,8 \mathrm{a}$ \\
Cinzas & $1,1 \mathrm{a}$ & $13,3 \mathrm{~b}$ & $28,6 \mathrm{c}$ & $47,1 \mathrm{~d}$ \\
\hline TBARS & $0,5 \mathrm{a}$ & $1,8 \mathrm{~b}$ & $2,2 \mathrm{~b}$ & $1,6 \mathrm{~b}$ \\
\hline Rendimento $(\%)$ & 38,4 & 30,5 & 19,3 & 14,8 \\
\hline
\end{tabular}

Médias seguidas de letras distintas na linha diferem entre si pelo teste Tukey $(\mathrm{P}<0,05)$.

TBARS: substância reativa ao ácido tiobarbitúrico - valores expressos em $\mathrm{mg}$ de malonaldeído/kg.

Tabela 2. Valores médios para composição centesimal e rendimento de filés de tilápia- do-nilo, submetidos ao processo de salga seca, antes e após secagem

\begin{tabular}{lcccc}
\hline Componente (\%) & Início & Antes secagem & Após secagem & Produto final \\
\hline Umidade & $80,0 \mathrm{a}$ & $48,3 \mathrm{~b}$ & $16,1 \mathrm{c}$ & $6,2 \mathrm{~d}$ \\
Proteína & $18,2 \mathrm{a}$ & $34,1 \mathrm{~b}$ & $51,8 \mathrm{c}$ & $59,4 \mathrm{~d}$ \\
Extrato etéreo & $1,7 \mathrm{a}$ & $4,6 \mathrm{~b}$ & $7,5 \mathrm{c}$ & $4,6 \mathrm{~d}$ \\
Cinzas & $1,0 \mathrm{a}$ & $17,9 \mathrm{~b}$ & $28,5 \mathrm{c}$ & $28,3 \mathrm{~d}$ \\
\hline TBARS & $0,5 \mathrm{a}$ & $3,0 \mathrm{bc}$ & $3,3 \mathrm{c}$ & $1,9 \mathrm{~b}$ \\
\hline Rendimento $\left.^{1} \%\right)$ & 37,3 & 22,5 & 14,2 & 12,4 \\
\hline
\end{tabular}

Médias seguidas de letras distintas na linha diferem entre si pelo teste Tukey $(\mathrm{P}<0,05)$.

TBARS: substância reativa ao ácido tiobarbitúrico - valores expressos em $\mathrm{mg}$ de malonaldeído/kg.

Os filés da salga em salmoura foram armazenados à temperatura ambiente após a secagem, por um período de 60 dias, e quinzenalmente foram retiradas amostras para as análises. Observaram-se variações no teor de umidade (Tab. 1), provavelmente em função da umidade relativa do ar. Os valores para cloreto nos filés atingiram 22,7\% com 45 dias de estocagem. Os filés da salga seca permaneceram armazenados à temperatura ambiente por 45 dias, devido aos reduzidos teores de água no músculo.

Em relação aos valores médios de TBARS (mg de malonaldeído $/ \mathrm{kg}$ ) dos filés salgados de tilápiado-nilo, constatou-se aumento até 30 dias, embora com algumas flutuações, ao longo do período de armazenamento à temperatura ambiente (Tab. 1 e 2). O aumento inicial e a diminuição nos valores de TBARS com a estocagem também foram observados por Beraquet et al. (1983) e Zapata et al. (1986). Esse fato pode ser atribuído às reações do malonaldeído, produzido na oxidação das gorduras, com as proteínas musculares (Seo, 1976).

Segundo Ogawa (1999), com valores acima de $2 \mathrm{mg}$ de malonaldeído $/ \mathrm{kg}$, o peixe pode apresentar odor e sabor característico de ranço. No entanto, não existem índices que limitem o grau de oxidação de lipídios em peixes salgados e secos, porém baixa oxidação é considerada normal e necessária para satisfazer o paladar de alguns consumidores de peixe salgado (Pinheiro, 1995).

Os valores médios da composição centesimal de filés, determinada no início do processo da salga, após a prensagem e após a secagem, são apresentados nas Tab. 1 e 2. O teor de água muscular na salga úmida foi reduzido em $27 \%$ após as operações de salga e prensagem e, em até $58 \%$, após a secagem. Na salga seca, a redução foi mais intensa, pois, no final do processo, o 
teor de umidade havia sido reduzido em $39 \%$ e, após a secagem, quase $80 \%$ em relação aos valores iniciais.

Como conseqüência da redução da umidade no processo da salga em salmoura saturada, o teor de proteína bruta no músculo aumentou de $14,8 \%$ para $20,1 \%$ após a prensagem, e para $29,4 \%$ após a secagem. Para a salga seca, os teores de proteína bruta aumentaram para $34 \%$ antes da secagem e para $51,8 \%$ após a secagem. Zapata et al. (1986) verificaram valores de $81,3 \%, 55,5 \%$ e $44,5 \%$ de umidade para músculo de tilápia fresco, salgado e prensado e seco em estufa, respectivamente. Elevações nas porcentagens de proteína nos produtos salgado e prensado e após a secagem também foram observadas pelos autores.

Os filés de tilápias que continham inicialmente $1 \%$ de gordura, após o processamento em salmoura saturada, alcançaram valores acima de $3 \%$, e, na salga seca, atingiram $7,5 \%$. As variações dos teores musculares médios de cinzas neste estudo são semelhantes às encontradas por Zapata et al. (1986), sendo que o aumento reflete a incorporação de sal pelo músculo durante os processos de salga, prensagem e secagem.

O valor médio de rendimento em filé com pele para tilápia (Tab. 1 e 2) foi próximo a 38\%, estando dentro da faixa citada por ContrerasGuzmán (2002), de 32,8 a $59,8 \%$ para peixes marinhos e de água doce. No desenvolvimento do processo de salga, ocorreu diminuição de peso dos filés, em torno de 15,5\%, após 156 horas na salga úmida. No caso da salga seca, o rendimento foi um pouco menor, alcançando $14,2 \%$ após secagem, em função da perda de umidade. A prensagem dos filés da salga úmida proporcionou $20,6 \%$ de perda de peso, e o rendimento em filés, nessa etapa, foi de 30,5\%. Com a secagem ocorreu diminuição de $50 \%$ em relação ao rendimento inicial, atingindo valor de $19,3 \%$. Machado (1984) obteve rendimento de 30,6\% após a salga e secagem do pargo inteiro, apenas eviscerado.

Os filés de tilápia-do-nilo salgados e secos após a salga úmida mantiveram as características próprias do produto praticamente estáveis até 45 dias de armazenamento, e o prolongamento do armazenamento até 60 dias à temperatura ambiente parece não ser recomendado. Os produtos finais resultantes da salga seca apresentaram teor de umidade muito baixo $(6 \%)$ e com altos níveis de extrato etéreo (4,6\%). Embora as observações tenham sido baseadas nas determinações de cloreto, TBARS e composição centesimal, outros indicativos, como análises sensorial e microbiológicas, se fazem necessários para qualificar o produto.

\section{CONCLUSÃO}

Os filés salgados em salmoura mantiveram as características do produto por um período de 45 dias, sendo este o processo recomendado como forma de conservação de filés de tilápia-do-nilo em temperatura ambiente.

\section{REFERÊNCIAS BIBLIOGRÁFICAS}

BERAQUET, N.J.; BARRERA, J.P.E. Salting of mackerel (Scomber japonicus). 1. Effect of temperature and method of preparation on salt uptake. Colet. ITAL, v.13, p.131-147, 1983.

BOERI, R.L.; MOSCHIAR, S.M.; LUPIN, H.M. Estudio comparativo de los processos de salado humedo e seco de merluza (Merluccius hubbsi). Rev. Agroq. Tecnol. Alim., v.22, p.139-145, 1982.

BURGESS, G.H.O; CUTTING, C.L.; LOVERN, J.A. et al. Salt curing In: BURGESS, G.H.O.; CUTTING, C.L.; LOVERN, J.A. et al. (Eds). Fish handling \& processsing. New York: Chemical Publishing, 1967. cap.5. p.102-119.

CHIRALT, A.; FITO, P.; BARAT, J.M. et al. Use of vacuum impregnation in food salting process. J. Food Eng., v.49, p.141-151, 2001.

CONTRERAS-GUZMÁN, E.S. Bioquímica de pescados e invertebrados. Santiago, Chile: Ed. CECTA-USACH, 2002. 309p.

HARTREE, E.F. Determination of protein a modification of de Lowry method that gives linear photometric response. Anal. Bioch., v.48, p.422-427, 1972.

MACHADO, Z.L. Tecnologia de recursos pesqueiros: parâmetros, processos, produtos. Recife: SUDENE-DRN-Div. Recursos Pesqueiros, 1984. 277p. 
MÉTODOS analíticos oficiais para controle de produtos de origem animal e seus ingredientes. I. Métodos Microbiológicos. Brasília: Ministério da Agricultura, 1993.

OFFICIAL methods of analysis. 14.ed. Washington: AOAC, 1990.

OGAWA, M. Tecnologia do pescado. In: OGAWA, M.; MAIA, E.L. (Eds). Manual de Pesca. Ciência e Tecnologia do Pescado. São Paulo: Varela, 1999. p.291-299.

PINHEIRO, C.R. Avaliação física, química e sensorial do pescado curado, In: SEMINÁRIO SOBRE TECNOLOGIA DE SALGA E DEFUMAÇÃO DE PESCADO, 1995. Campinas. Anais... Campinas, 1995. p.149-158.

SEO, C.W. Hidrocarbon production from freeze dried meats. J. Food Sci., v.41, p.594-597, 1976.

SGARBIERI, V.C. Proteina em alimentos protéicos. Propriedades-degradação-modificações. São Paulo: Varela, 1996. 517p.

SHENDERYUK, V.I.; BYLOWSKI, P.J. Salazón y escabechado del pescado. In:
SIKORSKI, Z.E. (Ed). Tecnologia de los productos del mar: recursos, composión nutritiva y conservación. Zaragoza: Editorial Acríbia. 1990. p.199-219.

THORARINSDOTTIR, K.A.; ARASON, S.; THORKELSSON, G. The effects of light salting on psicochemichal characteristics of frozen cod (Gadus morhua) fillets. J. Aquat. Food Prod. Technol., v.11, p.287-301, 2002.

USER's guide: statistics. Version 6. 4.ed. Cary, NC: SAS Institute, 1989.

VYNCKE, W. Direct determination of the thiobarbituric acid value in trichloroacetic extracts of fish as a measure of oxidative rancidity. Fette-Scifen Anstrichmittel, v.72, p.1084-1087, 1970.

ZAPATA, J.F.F.; MACEDO, B.A.; MARTINS, S.C.S. et al. Salga rápida e secagem da tilápiado-nilo (Sarotherodon niloticus). Bol. Soc. Bras. Cienc. Tecnol. Alim., v.20, p.17-28, 1986. 